\title{
É possível pensar a história em uma era pós-subjetiva?
}

\author{
Elías José Palti
}

Segundo destaca Manfred Frank em um artigo recente, a questão do sujeito constitui o tema fundamental em torno do qual se organiza toda a filosofia moderna. ${ }^{1}$ Em torno desse tema, por outro lado, se estabelece um vínculo entre filosofia, política e história que parece não ser simplesmente contingente. Segundo afirma, sem sujeito tampouco seria pensável a história, nem seria concebível alguma política libertadora. Assim, a "morte do homem", anunciada por Foucault, caberia ser interpretada como o anúncio de uma crise - não só teórica - que terminaria eliminando toda a expectativa de transcendência perante a ordem existente.

No entanto, e precisamente por isso, a "morte do sujeito" não poderia ser nunca, para Frank, definitiva. Na medida em que o sujeito é a condição de toda política e de toda história imagináveis, ele sempre, necessariamente, deverá retornar. De acordo com suas palavras:

Por um tempo a tese da "morte do sujeito" esteve na moda. Como todas as modas, esta já espera sua substituição a partir de uma mudança nos interesses atuais. Nietzsche, Heidegger e seus seguidores franceses tomam o sujeito como o reservatório da repressão do Ser e a origem da "vontade de poder". Suponhamos que haja algo certo nesta tese. Então, devemos dizer o seguinte: quem quer que ataque os efeitos perversos da tendência básica da filosofia ocidental que culmina com a "autopotencialização (self-empowerment) da subjetividade" pode fazê-lo razoavelmente, apenas no interesse da preservação dos sujeitos. Quem, senão um sujeito, pode ser assaltado e reprimido pelas normas do discurso ou pelas "disposições de poder" expressas pelos poderosos encantamentos de Foucault? Uma fibra celular no cérebro não pode sofrer uma "crise de sentido" pela simples razão de que só os sujeitos podem reconhecer algo como dotado de sentido. ${ }^{2}$

Certamente, se aceitamos a definição de Frank, o sujeito não poderia desaparecer sem que, com ele, desaparecessem a política e a história. Contudo, esta conclusão leva a que se perca de vista a questão que Foucault pretendia assinalar, quando discutiu a categoria de "Sujeito". O "Sujeito", a que se referia, tem um sentido específico; surge no marco de uma formação discursiva particular e carece de significado fora dela. Chegado a este ponto é necessário, portanto, uma distinção conceitual; concretamente, caberia precisar o que se entende, em cada caso, por "sujeito". Conforme veremos, a ideia de subjetividade sofreu, ao longo dos últimos quatro séculos, uma sucessão de redefinições fundamentais. Em última instância, que o sujeito seja o fundamento último da ética, ou da política, já pressupõe uma determinada definição do mesmo.

\section{As ambiguidades do sujeito moderno}

A confusão suscitada pelo conceito foucaultiano deriva, em grande medida, de problemas relacionados à polissemia do conceito de "sujeito". O próprio Foucault é, até certo ponto, responsável por muitos dos mal-entendidos que se estabeleceram em torno desta categoria, na medida em que buscou, de forma deliberada, trabalhar tal polissemia. Esta se liga estreitamente às ambiguidades próprias a outro conceito com o qual está intimamente associado: o de modernidade. Em A época da imagem do mundo, Heidegger estabelece a associação entre ambos os termos que logo se tornaria canônica. Para isto, partirá da análise de suas raízes etimológicas. O termo subjectum, segundo assinala, é a tradução latina do hypokeimenon a que se refere Aristóteles em suas Física e Metafísica. Subjectum, pois, indica o substrato da predicação (aquilo que sustenta, ou subjaz, a todos os seus predicados), cuja função é análoga à matéria (byle), a qual persiste através das mudanças de forma (morphê) que se impõem sobre ela. Em princípio, qualquer coisa ou ser de que se pudesse predicar algo seria "sujeito". A identificação do "sujeito" 
com o Eu, iniciada por Descartes, é, pelo contrário, o que marca a emergência do pensamento moderno. Com a modernidade, afirma Heidegger, "o Homem converteu-se em subjectum", ${ }^{3}$ fundamento último que torna o mundo inteligível, o qual, então, se vê reduzido ao status de mero objeto para o seu agir. Todavia, não é este, tampouco, o "Sujeito" a que se referia Foucault.

Ao "Homem tornado subjectum", Foucault associa condições histórico-epistemológicas precisas que, em As palavras e as coisas, sintetiza sob o conceito de "episteme moderna". Esta se desenvolveu no interior de um arco temporal precisamente delimitado: do final do século XVIII ao final do século seguinte. Ainda que nunca o afirme explicitamente, Foucault, certamente, tomou o termo, deliberadamente ambíguo, da expressão com que Hegel abre sua Fenomenologia do espírito: "trata-se de pensar o Absoluto não como substância, mas, também, como sujeito" ${ }^{4} \mathrm{O}$ "sujeito" de que Hegel fala, aqui, é um conceito reflexivo, um em si e para si: "o movimento de colocar-se a si mesmo ou a mediação de seu tornar-se outro". ${ }^{5}$ Sua origem se encontra intimamente associada ao processo de emergência de uma noção particular da temporalidade da qual, segundo a análise de Reinhart Koselleck, nasceu a ideia de História.

Com efeito, para Koselleck, a quebra da relação entre "espaço de experiência" e "horizonte de expectativas" - as duas "metacategorias" históricas fundamentais para a compreensão histórica - resultaria na destruição do ideal ciceroniano da historia magistra vitae, em que se fundavam todas as concepções históricas pré-modernas. A partir de então, o futuro já não seria legível, a partir das lições do passado. E ele assinala um modo inédito de experimentar a temporalidade da qual nasce a modernidade. A ideia de "progresso" da Ilustração é a tradução dessa experiência vivida da irreversibilidade temporal, condensada na "lei de aceleração do tempo", postulando que a mudança se produz segundo intervalos cada vez mais curtos de tempo. É somente, então, que surge o conceito de História como um "coletivo singular", isto é, como sujeito e objeto de si mesma.

Tal modo, para ele tipicamente "moderno" de experimentar a temporalidade, surge dos avanços técnicos produzidos no século XVIII, mas também, e fundamentalmente, da irrupção revolucionária. Esta introduziu uma nova consciência a respeito da construtibilidade da história, a saber, que esta é algo que os homens produzem com o seu próprio agir. A irreversibilidade temporal se ligaria, assim, à capacidade de ação do sujeito. Segundo afirma,

Os homens são responsáveis por suas histórias, nas quais se enredaram, [...] devem responder pela incomensurabilidade entre intenção e resultado [...]. Na história sucede sempre mais ou menos do que está contido nos dados prévios [...]. Sobre este mais ou este menos se encontram os homens. ${ }^{6}$

Koselleck sintetiza aqui a problemática do sujeito. A pergunta pelo "sujeito" é, efetivamente, a pergunta por esse mais (ou menos) que separa o consequente de seu antecedente, constitui a marca da contingência na história. A mesma se condensa na pergunta sobre como é possível que, se um estado "B" nasce de um estado "A", exista em "B" algo que, no entanto, não se encontrava já contido em "A". A resenha histórica dos diversos conceitos de "sujeito" que se sucederam nos últimos dois séculos nos permitirá, entretanto, precisar alguns dos conceitos mobilizados por Koselleck e compreender melhor como se produziu a passagem do Eu-Substância ao Eu-Sujeito (um deslocamento conceitual fundamental que, na perspectiva de Koselleck, tende a diluir-se) e, finalmente, como este último entra em colapso em fins do século passado, junto com aquelas condições histórico-epistemológicas nas quais havia surgido.

\section{Do Eu-Substância ao Eu-Sujeito}

O problema básico, na perspectiva de Koselleck, radica no fato de que, ao agrupar sob uma mesma categoria (a de "modernidade") o conjunto de correntes de pensamento surgidas nos últimos três séculos, tende-se a nivelar as diferenças entre formaçôes discursivas, na realidade, muito diversas entre si. Elas se veem então reduzidas a uma mera questão de graus (de acordo com a "lei de aceleração do tempo", o que mudaria entre o século XVIII e o século XIX seria o percentual de produção de mudanças; o 
mesmo, entre os séculos XIX e XX e, assim, sucessivamente). E, enfim, leva a perder de vista o processo do qual surge o conceito de "Sujeito" (que já não é "substância").

Em primeiro lugar, desde o momento em que associa a modernidade a um determinado conceito do tempo, como irreversível e linear, Koselleck se vê obrigado a deixar fora dela o espectro inteiro de filosofias da primeira modernidade. De fato, o ganho mais característico e determinante do aparecimento do que geralmente se conhece como Idade Moderna foi, precisamente, o desenvolvimento da noção de reversibilidade temporal. Esta noção se encontra perfeitamente formulada por Laplace e simbolizada em seu "pequeno demônio": aquele capaz de conhecer o universo completo em seu estado atual, dizia Laplace, "teria o passado e o futuro diante de si". ${ }^{7}$ Com esta ideia, Laplace tão somente conduzia o conceito newtoniano até as suas últimas consequências lógicas. Nele, a temporalidade não é um elemento constitutivo do universo físico; a assimetria entre passado e futuro derivaria somente das limitações de nossas capacidades cognitivas.

De fato, Koselleck confunde a noção de "progresso" da Ilustração com a de "evolução" que nasce no século XIX, quando aparece um novo paradigma da temporalidade associado à ideia de "irreversibilidade". O "sujeito" da Ilustração é, ainda, concebido em termos de "substância"; esse subjectum, de que falava Heidegger, que se mantém invariável por debaixo das mudanças de forma impostas de fora. É isto, definitivamente, o que explicaria a regularidade dos fenômenos e o caráter sistêmico da Ordem que lhe é subjacente. A ideia de contingência, não de todo estranha às filosofias da história da Ilustração, nelas se associaria ao velho tópico da fortuna: a mesma resultaria da presença inevitável de circunstâncias que escapam ao controle do sujeito. A mudança se impóe ao sujeito, portanto, de fora; longe de ser a fonte das mudanças, representa, pelo contrário, esse substrato unitário que confere estabilidade ao mundo (mutante e caótico), permitindo sua inteligibilidade.

A ideia de uma contingência imanentemente gerada nasce apenas com a emergência de um novo conceito histórico - já muito distinto do Ilustrado - a que tradicionalmente se define como "organicista”. Tal definição requer, no entanto, mais rigor. As filosofias da história da Ilustração não foram, de fato, menos "organicistas" do que as românticas. Contudo, a ideia de "organismo" sobre a qual aquelas se fundaram era muito diferente da que se impôs em seguida, no século XIX. Aquelas construíram seu modelo a partir do conceito de matriz pré-formista de "organismo". Conforme esta teoria, as formas dos indivíduos adultos estariam pré-formadas no embrião. Somente esta hipótese poderia admitir a ideia de um desenvolvimento imanente, autogerado. Do contrário, se o processo formativo fosse criativo, se os seres se transformassem em seu transcurso, sua convergência para formas específicas de vida (que permite a reprodução sistemática das espécies e confere estabilidade à ordem natural) obrigaria a se reintroduzir a hipótese de uma intervenção ou guia sobrenatural. Enfim, somente a hipótese de uma pré-formação orgânica permitiria conceber a natureza como um sistema. Sobre esta premissa edificou-se todo o saber da "história natural" da Ilustração e foi ela que, também, forneceu a base para as primeiras filosofias da história. O resultado disso é o conceito de "progresso", como um processo linear e cumulativo.

A ideia evolucionista surgiria, em contrapartida, de uma nova percepção da irreversibilidade temporal, e, com ela, da singularidade de todo acontecimento propriamente histórico. Os progressos verificados, no início do século XIX, no campo da embriologia, e que resultaram em uma nova noção de "organismo", foram cruciais para a elaboração de um conceito evolucionista da história. Karl von Baer (o "pai fundador" da embriologia moderna) é a figura-chave nesse processo de redefinição conceitual. De acordo com a teoria que formula em sua História da evolução dos animais (1828), o que se encontraria pré-formado no embrião não era nenhum conjunto de traços visíveis, mas o princípio de sua formação, isto é, certa ordem lógica de transformaçóes coordenadas e orientadas para a realização de uma finalidade imanente (algo parecido com o que chamamos, hoje, de "programa genético").

Abre-se, assim, uma primeira fissura entre consequente e antecedente. O que vem depois já não pode mais ser lido naquilo que existia antes. O tempo passa a ser um elemento constitutivo do universo físico (e moral). Todavia, não é este, ainda, o conceito de temporalidade que Koselleck atribui, retros- 
pectivamente, à "modernidade" em seu conjunto. Com efeito, se bem que para o idealismo alemão cada fato fosse absolutamente singular (ou seja, a história nunca se repetia), isso não significava que o futuro não estivesse, de algum modo, contido germinalmente no presente como um telos imanente. Segundo se pensava, assim como o presente nasce do passado, o futuro, ainda que não resulte por necessidade lógica do presente, deve se encontrar, de algum modo, já contido neste como uma de suas alternativas potenciais de desenvolvimento. Isso impõe, enfim, limites estreitos à "construtibilidade" da história. E articula-se ao último e mais fundamental fenômeno de singularização conceitual que se produz apenas com o idealismo, e que Koselleck, sugestivamente, evita em sua análise: a passagem dos sujeitos ao Sujeito. Então, o homem se converte, como os germes de von Baer, em um transcendental objetivo, pensado não como dado de uma vez e para sempre, mas como o princípio de suas próprias transformaçóes, como o movimento de colocar-se fora de si mantendo-se, ao mesmo tempo, ele mesmo. Enfim, um Sujeito que já não é mais uma substância anterior e independente de seus atributos, mas, uno e mesmo, com seus próprios predicados.

\section{Do Sujeito ao Ego}

A ideia de Koselleck do devir histórico se associa, como dissemos, à dissolução do conceito evolucionista de história que se produz apenas ao final do século XIX, quando o conceito de organismo perde suas anteriores conotações teleológicas. Emerge, então, a ideia da radical contingência e construtibilidade dos processos históricos. A ruptura do modelo evolucionista-pré-formista, produzida na biologia, é ilustrativa do novo paradigma de temporalidade que surge então. Em uma série de escritos iniciados em 1883, Weismann postula a ideia de uma descontinuidade radical entre organismo vivo (o indivíduo adulto) e germe, o que descarta a possibilidade da herança dos caracteres adquiridos. Isto tornaria inconcebível a ideia de que os processos evolutivos se produzem como resultado da acumulação gradual de pequenas modificações. Em 1900, Hugo de Vries desfere o golpe final nas concepções evolucionistas holístico-funcionalistas do século XIX. Para de Vries, os fenômenos evolutivos, no nível filogenético, resultam de transformações repentinas, ou mutações globais fortuitas. Desse modo, as mutaçôes (a mudança) se veem reduzidas a ocorrências imprevisíveis, geradas internamente, mas sem nenhuma meta ou finalidade perceptível. A noção de "totalidade" (estrutura) se desliga, então, da de "finalidade" (função), dissociando, por sua vez, as noções de necessidade e contingência.

A categoria de totalidade, agora, remeterá aos sistemas autointegrados, cuja dinâmica imanente tende à preservação de seu próprio equilíbrio (homeostasis) e à sua autorreprodução. A "historicidade" só pode vir, portanto, de fora deles, indicando a ação de uma esfera intencional transcendente. Poder-seia, talvez, ver aqui um retorno à ideia Iluminista de um sujeito transcendente. No entanto, em relação a ela, os significados se inverteram: a homogeneidade, a continuidade (a ordem) existem, agora, apenas no nível do mundo objetivo-fenomênico; o real-subjetivo, a estrutura subjacente ao universo (que não se pode ver, mas experimentar), é continuamente cambiante, caótica. O físico e filósofo Ėmile Boutroux, em De la contingence des lois de la nature (1874), foi o primeiro a assinalar que, como demonstra a termodinâmica, a estabilidade dos sistemas (tanto físicos como sociais) existe apenas no nível macroscópico, enquanto que no nível microscópico (em sua estrutura molecular) eles permanecem caóticos, sendo seu comportamento errático e imprevisível. As ciências, governadas por leis deterministas, só podem, pois, compreender as aparências externas dos sistemas; nunca podem penetrar - e dar conta de sua estrutura interna. O sujeito transcendental (a ação intencional) deixa, então, de ser garantia de ordem para se converter na origem e na fonte da contingência.

Não se trata, contudo, de uma simples inversão de sentidos. Mais importante ainda é o tipo de deslocamento que então se opera. O sujeito intencional já não é propriamente um sujeito, senão um Ego (o sujeito não tético) que precede à distinção entre sujeito e objeto; indica esse terreno pré-categorial e pré-discursivo no qual tanto o sujeito quanto o objeto podem se constituir como tais. Um e outro pres- 
supõem um mundo. O ego transcendental (que já não é um sujeito) é precisamente essa intuição primitiva $($ doxa $)$ reveladora de um mundo. Trata-se, pois, de remontar o fundado à contingência que o funda, reativar o momento do ato fundador sedimentado nas formas da ordem instituída.

A crítica estruturalista colocaria em questão os supostos essencialistas da tradição fenomenológicoexistencialista que supóe um Ser sob suas operações instituidoras (no ato de imaginação originária, o ego projetaria sua própria essência). Mas o certo é que, ao eliminar o sujeito, o estruturalismo tornava inconcebível a mudança; e isto, de algum modo, reconduziria, mais de uma vez, à ideia de um sujeito transcendente. De fato, o princípio estruturalista de que os fenômenos de ruptura resultam inexplicáveis racionalmente já pressupõe a ocorrência de fenômenos tais que só poderiam se produzir a partir da intervenção de algum agente externo às próprias estruturas. Definitivamente, a questão que o estruturalismo deixaria proposta é a de como pensar uma instância de transcendência sem postular a existência de um agente intencional, ou seja, sem cair em alguma forma de essencialismo. A busca por uma resposta a essa interrogação terminaria deslocando a episteme nascida da quebra das noções evolucionistas da história.

\section{Do Ego à khöra}

A mutação conceitual através da qual a oposição entre ação intencional (sujeito) e sistemas autorregulados (estrutura) perderia seu sentido anterior se articularia, novamente, a transformaçóes ocorridas no âmbito do pensamento científico. O pressuposto subjacente ao horizonte de pensamento em que se inscreve tal oposição é que, nas palavras de Meyerson, somente o que não muda é racional: uma vez que a razão só pode generalizar a partir do dado, o acontecimento (os fenômenos de ruptura) seria inapreensível através de conceitos. ${ }^{8}$ Entretanto, nos últimos vinte anos uma série de avanços teóricos vem convergindo no sentido de colocar em seu centro a noção de acontecimento, o que, em última instância, rompe com a ideia de uma oposição entre mudança e racionalidade.

A noção de acontecimento se relaciona aqui com a de metaevolução, isto é, a evolução dos próprios processos evolutivos. A representação dos processos auto-organizativos (autopoiéticos) ${ }^{9}$ levou ao desenvolvimento de modelos cibernéticos com retroalimentação positiva, ou seja, sistemas de autorregulação nos quais os desvios que aparecem tendem a ser reforçados por flutuações subsequentes. Os mecanismos de retroalimentação positiva dos deslocamentos determinam a abertura do sistema não só em relação aos produtos (os resultados) de sua atividade interna, mas, também, em relação às próprias regras que governam seu desenvolvimento. Esta capacidade autotransformadora é um correlato da noção de Prigogine de ordem através de flutuações, que define mais precisamente o caráter não linear, não teleológico, intrínseco aos processos metaevolutivos. ${ }^{10}$

No contexto dessas novas teorias, a ordem e o caos já não podem ser considerados como dois termos opostos, ou referirem-se a duas instâncias separadas em um processo evolutivo mais geral, mas, à própria atividade interna das estruturas. Estas oferecem um modelo (provêem um novo solo de positividades, para dizê-lo com as palavras de Foucault) para pensar um processo meta-evolutivo que contém a geração de contingências como uma dimensão imanente, sem pressupor, com isso, a ação por detrás de um Ser que preexiste às suas próprias condições de existência. Seguindo este modelo o sujeito já não é um Ser prévio às estruturas (o puro ato instituidor), nem, tampouco, um mero efeito de estrutura, mas um efeito de des-estrutura.

Atravessamos, assim, um novo umbral. Agora, nos transferimos para as condições de possibilidade do sujeito da ação intencional: todo ato instituidor pressuporia uma fissura ontológica, uma carência inerente que impede a clausura estrutural. Ou seja, para que exista sujeito, é necessário que antes se abra um espaço de indecisão (uma decisão determinada por uma regra já não é verdadeiramente uma decisão, mas apenas a aplicação da regra). Essa fissura ontológica é o que Derrida chamou khōra: o lugar de inscrição do ato instituidor (a khôra era aquele vazio no qual, segundo Platão, o demiurgo inscreveu os 
objetos). Tal deslocamento para as condições de possibilidade do sujeito não-tético, instalaria, enfim, um novo nicho epistemológico no qual se dissolve a oposição entre estrutura e sujeito (ego).

A pergunta que aqui se faz é como conceber a ideia de subjetividade em um terreno de objetividades prévio ainda à articulação pré-categorial de sentidos - que é o terreno do ego husserliano - abri-lo à interrogação sobre as suas próprias condições de possibilidade. E isso pressuporia um deslocamento conceitual fundamental. A categoria de sujeito indica, agora, não aquilo que funda o sentido, mas a instância em que o mesmo se rompe. O sujeito se identifica aqui, portanto, com aquela brecha assinalada por Koselleck que separa um estado consequente de seu precedente, sem, com isso, supor nenhum Ser sob o qual os sentidos emanam. É ali precisamente que nasce, para Badiou, a política. "O que faz sujeito em política", diz, "ainda que revelado em sua existência pelo próprio efeito político, segue sendo inarticulável nela". ${ }^{11}$

Segundo vemos, a questão do sujeito pode bem ser proposta nos termos encaminhados por Koselleck, isto é, remetendo àquela brecha que distancia um estado subsequente da situação precedente, instaura o vértice a partir do qual se desdobra o espaço da história, abrindo os sistemas à temporalidade. Ora, a afirmação de Koselleck de que por detrás daquele espaço, "mais ou menos, se encontram os homens" (ou seja, a ação intencional) é, como vemos, apenas uma das respostas possíveis para esta interrogação. Trata-se, mais especificamente, de uma resposta tipicamente neokantiana, segundo a qual o sujeito não é só a marca, mas a fonte da mudança em história (a origem do contingente). E é esta, mais precisamente, a que já havia se tornado insustentável. Abre-se assim o horizonte ao surgimento de uma era pós-subjetiva. E isto nos devolve à pergunta inicial feita por Frank: é possível pensar a História, uma vez que a ideia de um Sujeito se revelou uma ilusão, uma mera construção intelectual? Neste ponto devemos reconsiderar o segundo dos termos aqui examinados: a ideia de História.

\section{Pensar a História em uma era pós-subjetiva}

O que vimos anteriormente permite-nos introduzir uma precisão histórico-conceitual chave, com o objetivo de compreender o sentido da ruptura que inaugura a "era pós-subjetiva”. A ideia de História nasceu, em última instância, como resultado da grande crise que assaltou o pensamento ocidental nos séculos XVI e XVII. A interrogação que cruzaria a cultura do período é: como é possível a vida em comunidade, uma vez que fomos despojados da mão de Deus, reduzidos a uma vida puramente animal? O século XIX resolveria esta crise. Foi então que uma série de categorias - Nação, História, Razão, Revolução etc. - afirmaram-se, conduzindo-nos a um horizonte de inteligibilidade em nosso trato com um mundo já despojado de toda a garantia transcendente, tornando-o apreensível simbolicamente.

Koselleck analisou como se expressou essa grande virada da cultura ocidental, no campo da história conceitual, assinalando como surge ou se redefine um conjunto de categorias, e, em particular, como emerge a ideia de História, como um coletivo substantivo singular dotado de uma temporalidade própria. Seu surgimento situa-se, como já vimos, no que Koselleck denomina de Sattelzeit (período de transição entre o início da modernidade e a modernidade propriamente dita, ou período de gestação da modernidade), que se estende de 1750 a 1850. Longe de se constituir como uma categoria eterna, tratar-se-ia, pois, de um conceito relativamente recente; enfim, de uma construção intelectual contingente, que se sustenta em consequência de uma série de premissas que não são elas mesmas, em absoluto, autoevidentes. ${ }^{12}$

Esta construção logo se revelaria, ademais, claramente mítica, ou seja, fundar-se-ia em uma espécie de antropomorfização da História: a hipóstase e projeção sobre a mesma de traços e atributos que corresponderiam, na realidade, ao agir subjetivo. Ora, não é este conceito da História, como vimos, o que se encontraria hoje em questão. De fato, a ideia de que a história marcha por si mesma para a realização de seu próprio fim, para um destino que se encontra colado ao seu próprio conceito, já havia entrado em crise no início do século XX. O que entra em crise é outro conceito já muito distinto da História; crise essa nascida, precisamente, do colapso das visões evolucionistas próprias do século XIX. O 
que surgiria no contexto da grande crise finissecular, a qual, como já se assinalou, atravessa o conjunto do pensamento e leva ao desmantelamento das perspectivas teleológicas da história, teria sido uma nova perspectiva, através da qual se situaria, agora, no centro da história, o próprio agir subjetivo. Já não se poderia confiar que a própria marcha espontânea da história exibisse seus fins próprios, mas que, agora, caberia ao sujeito orientar o seu desenvolvimento. A história se converteria então, fundamentalmente, em um ato de autoafirmação subjetiva. É nesse momento que se impõe a premissa de que é o homem que constrói a história, projetando-lhe, mediante seu próprio agir, um sentido e uma direção a um mundo que, por si mesmo, já não tem nenhum.

É também nesse contexto intelectual que, como vimos, instala-se a própria ideia koselleckiana de História como uma construção subjetiva (e que Koselleck projeta retrospectivamente sobre a Ilustração). Ora, é aqui que se faz necessária uma segunda precisão histórico-conceitual. Como assinalamos, o que havia entrado em crise em fins do século XX já não seria a ideia de que a história marcha por si mesma para a realização de um fim (algo que já havia ocorrido, como indicamos, há mais de um século), mas, este outro pressuposto de que são os sujeitos que constroem a história (que eles sejam, de algum modo, seus demiurgos), uma ideia que se tem revelado não menos mítica do que a visão evolucionista-teleológica da História; somente uma forma distinta de ilusão antropomórfica. Definitivamente, é a própria categoria de Sujeito que entrou em crise agora. O que nos resta então? Uma situação em que, não só já não há nenhum suporte objetivo, nenhuma garantia objetiva ao agir subjetivo (a confiança em que a marcha espontânea da história impulsionasse a realização de nossos próprios ideais), como também nenhum suporte objetivo que possa sustentá-lo, nenhum Sujeito capaz de construir a História.

Em última instância, a ideia de que são os sujeitos que constroem a História tinha ainda como seu pressuposto a ideia da existência de algo como uma História. De fato, teleologismo objetivo e teleologismo subjetivo se opõem, mas, simultaneamente, se supõem mutuamente. Assim como sem Deus, tampouco a História poderia se sustentar, despojado do tipo de transparência que a ideia de História lhe provia, o Sujeito não tardaria em revelar seu fundo metafísico. A pergunta que surge, então, é: como é possível pensar a política e a história, quando todo o universo categorial em que tais conceitos se fundavam já se rompeu? Todavia, o que dá um sentido perturbador a esta interrogação - o que descobrimos agora - é que, depois da quebra do Sentido, ainda assim, não podemos prescindir dele, simplesmente porque sem ele não é possível sustentar a vida coletiva. Definitivamente, a interrogação proposta por Frank seria perfeitamente legítima. Contudo, sua formulação contém uma falácia implícita: do fato de que sem sujeito não seja possível a história não se depreende que este efetivamente exista, ou que deva existir. Ou seja, Frank toma por solução o que nada mais é do que a formulação de um problema que ainda precisa ser desenvolvido, evitando-o, esvaziando-o, enfim, daquele conteúdo profundamente dilemático, implícito em sua própria interrogação. O certo, de todo modo, é que tampouco conseguiriam resolvê-lo aqueles que optam por uma via oposta à de Frank, ou seja, converter a crise da ideia de História na base para uma reformulação da ideia de agência subjetiva que, longe de deslocá-la, permita reafirmá-la sobre bases ainda mais sólidas.

Um representante dessa linha de pensamento é Zygmunt Bauman. Em seu livro Legisladores e intérpretes afirma que, uma vez quebrados os pressupostos teleológicos e desfeitas as ilusões de cientificidade da história, a função do historiador já não seria, na verdade, tratar de descobrir os fins para os quais, supostamente, aquela se orienta (ideia que seria vista, agora, como um mera versão secularizada do desígnio providencial), mas, algo muito mais modesto: ampliar nosso horizonte cultural, trabalhando como tradutor, como intérprete; enfim, colocando-nos em contato com aquelas culturas e realidades que são completamente estranhas para nós. ${ }^{13}$ Mas, para fazer com que essas culturas e realidades estranhas tornem-se familiares, o historiador deve, ao mesmo tempo, tornar estranho o familiar, ou seja, retirar o véu de naturalidade com que nossas crenças e realidades presentes se nos aparecem.

Desta perspectiva, o sentido que se encontraria na história, a partir da quebra de toda ilusão de sentido, a partir da revelação de seu caráter ilusório, consistiria no fato de que, ao confrontarmo-nos com 
este vazio de sentido, com a contingência dos fundamentos de nossos modos de convivência coletiva, isto nos permitiria minar as identidades substantivas e desenvolver um sentido de tolerância para com o outro, para com o que nos é estranho, o que é o pressuposto de uma democracia pluralista. Deste modo, abrir-se-iam as portas para uma forma inversa de cumplicidade entre saber histórico e vida, entre o âmbito fático e o reino dos valores. Já não é a missão da história criar sentidos ilusórios de comunidade imaginada, mas revelá-la justamente como tal. E é isso que alinharia a escrita da história em uma direção democrática. Assim, paradoxalmente, o horizonte para o qual teria que orientar-se o pensamento histórico neste último fim de século obteria seu sentido já não mais da busca de afirmação de alguma Verdade, mas da desestabilização de toda ilusão de sentido. No entanto, esta resposta tampouco poderá escapar do paradoxo.

Esta perspectiva do historiador como intérprete apresenta, basicamente, dois dilemas. Em primeiro lugar, ela pressupõe a possibilidade de um distanciamento em relação às nossas presentes certezas, de alcançar um ponto arquimédico, desde o qual seja possível ter acesso àquilo que nos é estranho como tal, ou seja, sem reduzi-lo ao que nos é familiar, sem simplesmente projetar nossas próprias crenças sobre ele. Definitivamente, esta perspectiva pressupóe um conceito de Verdade (neutralidade) que a própria ruptura dos supostos teleológicos, a que a disciplina histórica deve sua origem, seria hoje impossível de continuar sustentando. Assim, o próprio deslocamento dos teleologismos que abre as portas à ideia do historiador como intérprete será também o que irá minar o suposto no qual esta ideia se funda. Enfim, como dizíamos, sem o apoio da objetividade que os marcos teleológicos proviam, as projeçóes subjetivas de sentido tornar-se-iam constitutivamente precárias. E isto nos leva ao segundo dos dilemas mencionados.

Ele nos conduz a esta questão, ainda mais radical: até que ponto é possível afirmar que o solapamento das identidades levará realmente a um maior pluralismo e não terminará, pelo contrário, conduzindo à anomia, à revelação da total falta de sentido de nossa existência coletiva; se não nos dissolverá, definitivamente, em uma existência mecânica, fantasmagórica, repetitiva; enfim, se não se deveria, aqui, voltar a Nietzsche, quando afirmava a existência de uma incompatibilidade entre história e vida, ou seja, se a revelação da contingência dos fundamentos de nossa existência e valores presentes, longe de resultar em uma cultura mais pluralista e democrática, destruiria todo o sentido de comunidade. De algum modo inverte-se, assim, a problemática proposta. Em relação à missão da escrita da história, a pergunta que surge, agora, é esta: se a história, mais do que desnudar as ilusões de sentido, não deveria servir para criar sentidos de comunidade, isto é, para construir mitos de identidade, em um momento em que, no entanto, já se sabe o que são e que, portanto, não se pode acreditar neles.

\section{O sentido depois do Sentido}

Retornando agora à nossa interrogação original: o que significa dizer que vivemos numa era póssubjetiva ou, caso se queira, pós-secular? Esta pergunta nos leva à outra anterior. O que entendemos por uma era secular? Aqui se faz necessária uma nova distinção conceitual. Quando afirmamos (ou afirmávamos) que vivemos (ou vivíamos) em uma era secular, não nos referimos (ou referíamos) a mudanças ocorridas no nível das crenças ou das ideias dos agentes, mas nas suas condiçóes objetivas de enunciação, isto é, no horizonte de inteligibilidade em que tais crenças se inserem e tomam sentido. De fato, a maior parte da população, hoje, crê em Deus e tem ideias religiosas. Se considerarmos as estatísticas, deveríamos concluir que nosso mundo não está tão distante do século XIII. E, não obstante, sabemos que não é assim, que "Deus morreu". Esta, contudo, não é uma questão estatística (que percentagem da população deve crer, ou deixar de crer, para que se possa dizer que vivemos em um mundo secular?); nem algo que remeta estritamente às ideias dos sujeitos. Com efeito, não é no plano das crenças subjetivas que podemos encontrar o sentido das mudanças conceituais que acarretaram o "desencantamento do mundo" ocasionado com a chegada da modernidade. 
O que é, portanto, o que nos permite falar de uma "era secular"? É o fato de que, a partir de determinado momento, mais além (ou mais aquém) das crenças dos sujeitos, nosso mundo já não funcionará sobre a base do pressuposto da existência de Deus. Ferdinand Laplace (o astrônomo líder da França, ao final do século XVIII, que completou o sistema astronômico newtoniano) expressou isso muito bem. Quando Napoleão o censura reclamando que em seu sistema já não havia lugar para Deus, Laplace lhe responde: "Essa é uma hipótese da qual posso prescindir". E, com efeito, quando afirmava isso, Deus já havia se convertido em uma hipótese que se podia dispensar; havia-se revelado que tanto o mundo natural quanto o social podiam se sustentar por si mesmos, sem necessidade de uma garantia e sanção transcendente; algo que não foi simples de descobrir, nem era de todo claro, sequer que fosse possível verificar.

Podemos retornar agora à pergunta sobre o que significa, pois, dizer que vivemos numa era pós-subjetiva ou pós-secular. Novamente, isto não remete ao plano das crenças subjetivas, mas ao fenômeno do deslocamento objetivo desses horizontes de sentido que serviam de suporte à inteligibilidade histórica. Então, os historiadores descobriram que a nação não é mais do que uma invenção recente e relativamente arbitrária; a história, uma construção narrativa, e assim sucessivamente. Não se trata tanto que os sujeitos tenham mudado suas crenças, mas do fato de que as próprias condiçõos de articulação pública desses discursos tendem a revelar sua precariedade. Também os ideais de liberdade, democracia etc. desnudarão prontamente seu fundo aporético $;^{14}$ encontrarão sempre seus limites inerentes, suas premissas negadas. Enfim, privados de toda garantia transcendente, estas projeções de sentido não poderão evitar verem-se confrontadas com a evidência da radical contingência (arbitrariedade) de suas origens e fundamentos, sua falta de sentido última. Isto define, precisamente, o que podemos chamar de "segundo desencantamento do mundo". Que vivemos em um mundo pós-subjetivo ou pós-secular significa que, não só, Deus nos abandonou, mas que seus arremedos seculares (a Liberdade, a Nação, a Democracia, a Justiça, a História) perderam também sua eficácia como provedores primitivos de sentido (como conceitos articuladores de mundos). Chegado a este ponto, no entanto, como vimos, é necessária outra distinção conceitual.

Este "segundo desencantamento do mundo" atravessará, de fato, dois umbrais sucessivos, que cabe discernir. O que assistimos hoje é, mais precisamente, ao fim do século XX. O que é este século XX a que nos referimos? É o que, em um trabalho recente, Alain Badiou definiu como o século da "paixão pelo Real". ${ }^{15} \mathrm{E}$ isto o distingue radicalmente do modo com o qual o século XIX se confrontou com a pergunta pelo sentido do mundo e da história, já privados, então, de todo sentido transcendente. O século XIX foi, basicamente, um século de confiança na marcha espontânea da história, cujo desenvolvimento de suas próprias tendências e forças imanentes conduziria à realização daqueles fins que estavam, supostamente, contidos em seu interior. Sua realização se pensava sempre, no entanto, como projetada em um horizonte futuro, mais ou menos vago. O século XX aparecerá, por outro lado, como aquele no qual o advento desse horizonte último de sentido havia se tornado iminente, o momento em que as projeções de sentido deviam finalmente dar conta de sua realidade. Mas a sua execução suporia, agora, uma ação subjetiva que passaria, então, a se colocar em primeiro plano. Assim, o Sentido tornara-se, ao mesmo tempo, mais urgente e menos seguro. Sua realização já não será algo inelutável; sua necessidade já não se encontra inscrita em seu próprio conceito. Em suma, o fim do século XIX marcará também o momento da ruptura da objetividade do Sentido.

O conteúdo trágico do século XX está dado, precisamente, por essa necessidade de projetar ilusões de sentido privadas já da transparência que provinha do tipo de objetividade oferecida por uma filosofia da história, de um modelo teleológico de desenvolvimento em que se sustentar. Encontramos aqui o primeiro umbral a atravessar nesse percurso para o novo mundo pós-secular. Restará, ainda, mais um que é, precisamente, o que nos encontramos percorrendo, hoje. Haverá, assim, de romper-se finalmente com essa espécie de dialética trágica, essa simultânea necessidade-impossibilidade de sentido, que nos acompanhou ao longo do século XX. O que marca a passagem para a nossa era pós-secular é o fato de que, hoje, estão a ver-se minadas, também, aquelas projeções de horizontes de sentido ligadas a uma 
afirmação subjetiva dos valores. Há que se dizer, retrospectivamente, que aquelas já eram constitutivamente precárias. Assim como sem Deus tampouco poderia se sustentar a Verdade, sem uma Verdade, privado do apoio da objetividade provida pelos marcos teleológicos, o agir intencional subjetivo, alçado a suporte último do Sentido, tampouco poderia sustentar por si próprio o peso de investir valorativamente em um mundo e um devir já despojados de todo sentido transcendente, ou conteúdo ético. O fim do século XX marcará, finalmente, o momento da ruptura, não só da objetividade do Sentido, mas do próprio Sentido. Aqueles ideais que orientavam essa ação subjetiva (a Nação, a História, a Revolução, a Liberdade, toda espécie de arremedos seculares de Deus) revelarão, então, seu caráter ilusório, definitivamente mítico, nas palavras de Ernesto Laclau.

A ruptura do Sentido é, pois, aquele momento em que o nosso agir coletivo se vê esvaziado de sustentação, ou seja, privado tanto de garantia objetiva como de suporte subjetivo. Mas também - e é isto o que distingue esse segundo desencantamento do mundo em relação ao anterior - aquele em que descobrimos, contudo, que não podemos dele nos desprender (do Sentido). Precisamente porque a única forma de fazê-lo, de escapar do Sentido, é encontrando uma Verdade, que é, justamente, o que hoje se tornou inviável. Dá-se, assim, o paradoxo de que é a própria quebra do Sentido o que nos obriga a perseverar nele. A diferença fundamental que distingue nossa época pós-secular em relação à era secular anterior é, enfim, que o Sentido, diferentemente de Deus, não é uma hipótese da qual possamos prescindir. Encontramos aqui, portanto, a formulação mais precisa da pergunta sobre o que significa pensar historicamente em uma era pós-secular. Ela se traduz por qual é esse sentido que se abre após a quebra do Sentido; qual é a forma de pensamento histórico que nasce ou a que dá lugar uma era em que, não só Deus nos abandonou, mas em que, também, todos os seus arremedos seculares tenham perdido sua eficácia anterior, mas que, ainda então, não podemos, segundo descobrimos, desprendermo-nos de toda ilusão de sentido sem que possamos já acreditar nele, na medida em que se há revelado como tal. ${ }^{16}$

\section{Tradução: Rita Veiga Revisão técnica e edição: Maria Aparecida Rezende Mota}

\section{Notas}

${ }^{1}$ FRANK, Manfred. Is subjectivity a Non-Thing, an Absurdity [Unding]? On Some Difficulties in Naturalistic Reductions of Self-Consciousness. In: AMERIKS, Karl \& STURMA, Dieter (comps.). The Modern Subject. Conceptions of the Self in Classical German Philosophy. New York: State University of New York Press, 1995, p. 177.

${ }^{2}$ Ibid.

3 "O homem passa a ser aquele existente no qual se funda todo o existente à maneira de seu ser e de sua verdade. O homem se converte em meio de referência do existente como tal. Mas isso só é possível se se transforma a totalidade do existente. Em que se expressa essa transformação? O que é, de acordo com ela, a essência da Idade Moderna? [HEIDEGGER, Martin. La época de la imagen del mundo. In:___. Sendas perdidas (Holzwege). Buenos Aires: Editorial Losada, 1960. p. 79]. "Der Mensch wird zur Bezugsmitte des Seienden als solchen. Das ist aber nuch möglich, wenn die Auffassung des Seienden im Ganzen sich wandelt. Worin zeigt sich diese Wandlung? Was ist ihr gemä das Wessen der Neuzeit?” [HEIDEGGER, Martin. Die Zeit des Weltbildes (1938). In: . Holzwege. Gesamtausgabe, Band 5. Frankfurt am Main: Vittorio Klostermann, 1977. s. 88].

${ }^{4}$ HEGEL, G. W. Friedrich. Fenomenología del espiritu. México: Fondo de Cultura Económica, 1985, p. 15.

${ }^{5}$ Ibid, p. 15-6.

${ }^{6}$ KOSELLECK, Reinhart. Futuro pasado. Barcelona: Paidós, 1993, p. 265-6.

${ }^{7}$ LAPLACE, Pierre. A Philosophical Essay on Probabilities. New York: Dover, 1951. Sobre a ideia de "pequeno demônio" de Laplace ver, também, CASSIRER, Ernst. Determinism and Indeternism in Modern Physiscs. New Haven: Yale University Press, 1956, p. 3-25.

${ }^{8}$ A razão, dizia Meyerson, "procede de identidade em identidade, de modo que não pode representar-se a diversidade da natureza”. (MEYERSON, Emile. Identity and Reality. Londres: Allen \& Unwin, 1964, p. 399). 
${ }^{9}$ Ver MATURANA, Humberto. Biology of Cognition. Urbana: University of Illinois Press, 1970; MATURANA, Humberto \& VARELA, Francisco. Autopoietic Systems. Urbana: University of Illinois Press, 1975 e JANTSCH, Erich. The Self-Organizing Universe. Oxford: Pergamon Press, 1989.

${ }^{10}$ Ver PRIGOGINE, Ilya \& STENGERS, Isabelle. La nueva alianza. Madrid: Alianza, 1990 e Entre el tiempo y la eternidad. Madrid: Alianza, 1990.

${ }^{11}$ BADIOU, Alain. ¿Se puede pensar la politica? Buenos Aires: Nueva Visión, 1990, p. 59.

${ }^{12}$ Da História poder-se-ia dizer, enfim, o mesmo que Joseph de Maistre dizia do Homem, quando afirmava que havia visto muitos polacos, franceses, alemães etc., mas que jamais havia visto um Homem. Do mesmo modo, todos nós temos visto uma pluralidade de acontecimentos, fatos etc., mas jamais se nos deparamos com a História.

${ }_{13}$ BAUMAN, Zygmunt. Legisladores e intérpretes. Sobre la modernidad, la posmodernidad y los intelectuales. Buenos Aires: Universidad Nacional de Quilmes, 1997.

${ }^{14}$ Sobre o fundo aporético das categorias políticas modernas, ver ROSANVALLON, Pierre. Por una historia conceptual de lo político. Buenos Aires: FCE, 2003.

${ }^{15}$ BADIOU, Alain. El siglo. Buenos Aires: Manantial, 2005.

${ }^{16}$ A estrutura de pensamento a que dá lugar uma era pós-secular é o tema que desenvolvo em meu livro Verdades y saberes del marxismo. Reacciones de una tradición politica ante su "crisis". Buenos Aires: FCE, 2005.

\section{RESUMO}

O ensaio discute as categorias de sujeito, temporalidade e modernidade, a partir do empreendimento teórico de Koselleck, nos marcos do debate contemporâneo em torno das articulaçôes entre filosofia, história e política. O exame das mutaçôes conceituais experimentadas, no tempo, pela ideia de subjetividade, desde a sua origem às formulaçôes mais recentes, propóe pensar a História, isto é, a agência humana, em uma era pós-subjetiva marcada pela ruptura de qualquer projeto de sentido.

Palavras-chave: sujeito, subjetividade, temporalidade, história dos conceitos.

\section{ABSTRACT}

This essay examines the categories of subject, temporality and modernity, from the theoretical enterprise of Koselleck, considering the contemporary debate on the articulation between philosophy, history and politics. Following the conceptual changes experienced by the idea of subjectivity, from its origin to the most recent formulations, the essay explores to think History, that is, human agency, in a post-subjective age characterized by the disruption of any proposal of meaning.

Keywords: subject, subjectivity, temporality, Conceptual History. 